Article

\title{
Acetylation of alcohols and phenols under solvent-free conditions using iron zirconium phosphate
}

\author{
Abdol R. Hajipour a,b,*, Hirbod Karimi a,c, Amir Masti ${ }^{\mathrm{a}}$ \\ a Pharmaceutical Research Laboratory, Department of Chemistry, Isfahan University of Technology, Isfahan 84156, Iran \\ b Department of Neuroscience, University of Wisconsin, Medical School, Madison, WI 53706-1532, USA \\ c Young Researchers and Elite Club, Shahreza Branch, Islamic Azad University, Shahreza, Iran
}

\section{A R T I C L E I N F O}

Article history:

Received 24 November 2014

Accepted 26 December 2014

Published 20 April 2015

\section{Keywords:}

Iron zirconium phosphate

Nanoparticle

Acetylation

Alcohol

Phenol

Solvent-free condition

Solid catalyst

\section{A B S T R A C T}

Iron zirconium phosphate (ZPFe) nanoparticles were found to function as an efficient catalyst for the acetylation of a wide range of alcohols and phenols using acetic anhydride, generating good to excellent yields under solvent-free conditions. The steric and electronic properties of various substrates had a significant influence on the reaction conditions required to achieve the acetylation. The catalyst used in the current study was characterized by inductively coupled plasma-optical emission spectrometry, X-ray diffraction, $\mathrm{N}_{2}$ adsorption-desorption, scanning electron microscopy, and transmission electron microscopy. These analyses revealed that the interlayer distance in the catalyst increased from 7.5 to $9.3 \AA$ when $\mathrm{Fe}^{3+}$ was intercalated between the layers, whereas the crystallinity of the material was reduced. This nanocatalyst could also be recovered and reused at least six times without any discernible decrease in its catalytic activity. This new method for the acetylation of alcohols and phenols has several important advantages, including mild and environmentally friendly reaction conditions, as well as good to excellent yields and a facile work-up.

(C) 2015, Dalian Institute of Chemical Physics, Chinese Academy of Sciences. Published by Elsevier B.V. All rights reserved.

\section{Introduction}

$\alpha$-Zirconium phosphate (ZP) is one of the most important compounds in inorganic chemistry, and the layered structure of this material has led to its use in a variety of different fields [1-3]. ZP behaves as a unique ion exchanger because of its exceptionally poor aqueous solubility, high thermal stability, resistance to radiation and abrasive properties [4,5]. The $\mathrm{H}^{+}$of the $\mathrm{P}-\mathrm{OH}$ moiety in $\mathrm{ZP}$ can be exchanged for various other ions, resulting in an enlargement of the interlayer distance [6-9]. Several studies pertaining to the successful exchange of this proton with various divalent and trivalent cations, including $\mathrm{Mn}^{2+}, \mathrm{Co}^{2+}, \mathrm{Ni}^{2+}, \mathrm{Cu}^{2+}, \mathrm{Fe}^{2+}, \mathrm{Fe}^{3+}$, and $\mathrm{Zn}^{2+}$, have been presented in the literature [10-14]. It has also been reported that ZP pos- sesses excellent selectivity towards $\mathrm{Pb}^{2+}, \mathrm{Zn}^{2+}$, and $\mathrm{Fe}^{3+}$ as an ion exchanger [15-17]. Furthermore, ZP has been shown to exhibit antibacterial activity when loaded with $\mathrm{Cu}^{2+}, \mathrm{Zn}^{2+}$, or $\mathrm{Ce}^{3+}[5,6,13,14]$. There have also been several reports concerning the catalytic activities of ion-exchanged materials of this type, including the use of zinc zirconium phosphate (ZPZn) as a catalyst in the acetylation of alcohols and phenols and the use of copper zirconium phosphate (ZPCu) as a catalyst during the selective oxidation of alcohols [18-24].

The protection and deprotection of organic functional groups are important during multi-step organic syntheses. The particular functional group transformation chose is based on considering the simplicity of the reaction, as well as the ability to obtain high yields of the desired products and short reaction

\footnotetext{
* Corresponding author. Tel: +98-0311-3913262; Fax: +98-0311-3913252; E-mail: haji@cc.iut.ac.ir This work was supported by the Isfahan University of Technology (IUT), IR Iran. 
times, and to achieve a low cost process with an easy work-up $[25,26]$. The acetylation of alcohols, phenols, thiols, and amines is one of the most important and frequently used transformations in organic synthesis, especially in the synthesis of natural compounds, biologically active compounds, and polyfunctional molecules such as nucleosides, carbohydrates, chalcones, flavanones, naphthoquinones, pesticides, and steroids. Acetylated groups are also commonly found in cosmetics and food stuffs, as well as in solvents, perfumes, plasticizers, flavors, polymers, and pharmaceuticals [25-27]. One of the most common examples of a compound containing an acetylated group is acetylsalicylic acid (trademarked as Aspirin), which is produced by the acetylation of salicylic acid with acetic anhydride (AA) in the presence of an acid catalyst [28]. The acetyl group is one of the most inexpensive and commonly used protecting groups for $-\mathrm{OH},-\mathrm{SH}$, and $-\mathrm{NH}_{2}$ moieties because the resulting acetylated compounds are stable under a variety of reaction conditions and in contact with a wide range of reagents. Furthermore, the acetyl group can be readily introduced using inexpensive reagents and is easily removed by mild alkaline hydrolysis [29-31].

A number of different procedures have been developed for the acetylation of alcohols, phenols, amines, and thiols using both homogeneous and heterogeneous catalysts. These have included $\operatorname{VIV}(\mathrm{TPP})(\mathrm{OTf})_{2}$ [27], $\mathrm{La}\left(\mathrm{NO}_{3}\right)_{3} \cdot 6 \mathrm{H}_{2} \mathrm{O}$ [29], $\mathrm{B}\left(\mathrm{C}_{6} \mathrm{~F}_{5}\right)_{3}$ [30], NSPVPHS [31], $\mathrm{ZnCl}_{2}$ [32], borated zirconia [33], $\mathrm{ZnO}_{2}$ [34], $\mathrm{Ce}(\mathrm{OTf})_{3}$ [35], $\mathrm{SiO}_{2}-\mathrm{ZnCl}_{2}$ [36], $\mathrm{H}_{3} \mathrm{PW}_{12} \mathrm{O}_{40}$ [37], DMAP·HCl [38], $\mathrm{Cu}\left(\mathrm{BF}_{4}\right)_{2}$ [39], silica-bonded sulfamic acid [40], $\mathrm{Cp}_{2} \mathrm{ZrCl}_{2}$ [41], [TMBSA][HSO 4 ] [42], [bmim][OTs] [43], [MMPPA] $\left[\mathrm{HSO}_{4}\right]$ [44], SaSA [45], SBNPSA [46], SuSA [47], P(4-VPT) [48], acylimidazolium acetate [49], polyvinylpolypyrrolidoniume tribromide [50], $\mathrm{ZnAl}_{2} \mathrm{O}_{4} @ \mathrm{SiO}_{2}$ [51], $\mathrm{P}_{2} \mathrm{O}_{5} / \mathrm{Al}_{2} \mathrm{O}_{3}$ [52], $\left[\mathrm{Hmim}_{3} \mathrm{HSO}_{4}\right.$ [53], yttria-zirconia [54], $\mathrm{CoCl}_{2}$ [55], MWCNTs-C- $-\mathrm{PO}_{3} \mathrm{H}_{2}$ [56], $\mathrm{NiCl}_{2}$ [57], $\mathrm{Ni} / \mathrm{SiO}_{2}$ [58], DBSA [59], rice husk [60], anhydrous $\mathrm{NiCl}_{2}$ [61], $\mathrm{LaFeO}_{3} / \mathrm{SiO}_{2}$ [62], and Fe/SBA-15 [63]. However, most of these catalysts have both advantages and limitations. Despite extensive interest in the development of new methods of acetylation, there is still a requirement to develop simple, efficient, inexpensive, widely applicable, reusable, and environmentally benign catalysts and procedures capable of promoting the acetylation process. With growing environmental concerns, one of the most promising ways to achieve these goals appears to be the use of environmentally friendly insoluble catalysts and/or solvent-free conditions. An insoluble catalyst may be readily recovered from the post-reaction mixture by simple filtration and potentially recycled and reused several times, making the process more economically and environmentally viable. Furthermore, reported examples have demonstrated that heterogeneous catalysts typically require less labor-intensive work-up procedures. Solvent-free synthetic methods are also valuable for both environmental and economic reasons [22,24]. With this in mind, and as part of ongoing work towards the development of efficient green catalysts for organic transformations $[64,65]$ with a particular emphasis on the acetylation and acylation of aromatic compounds [52,53], we report herein the use of iron zirconium phosphate (ZPFe) as an efficient catalyst for the mild, simple acetylation of alcohols and phenols under solvent-free conditions. This new ZPFe catalyst was characterized by inductively coupled plasma-optical emission spectroscopy (ICP-OES), X-ray diffraction (XRD), $\mathrm{N}_{2}$ adsorption-desorption, scanning electron microscopy (SEM), and transmission electron microscopy (TEM).

\section{Experimental}

\subsection{Catalyst synthesis}

All the reagents and solvents used in the current study were purchased from the Merck Chemical Company and used without further purification. The catalyst was prepared according to previously published procedures, with minor modifications [2,8-10]. As an initial step, ZP was synthesized according to the following procedure. $\mathrm{ZrOCl}_{2} \cdot 8 \mathrm{H}_{2} \mathrm{O}(5 \mathrm{~g})$ was heated under reflux conditions in a solution of $\mathrm{H}_{3} \mathrm{PO}_{4}(50 \mathrm{~mL}, 12 \mathrm{~mol} / \mathrm{L})$ for 24 $\mathrm{h}$. The resulting mixture was cooled to ambient temperature to give a suspension. After filtration, the filter cake was washed with a solution of $\mathrm{H}_{3} \mathrm{PO}_{4}(0.1 \mathrm{~mol} / \mathrm{L})$ until the filtrate was free of chloride ions. The filter cake was then washed several times with distilled water until the $\mathrm{pH}$ of the filtrate was neutral. The remaining solid was dried in an oven at $110{ }^{\circ} \mathrm{C}$ for $24 \mathrm{~h}$ [2]. ZPFe was prepared through an ion-exchange reaction [8-10]. Briefly, ZP (3 g) was dispersed in deionized water $(50 \mathrm{~mL})$ at $50{ }^{\circ} \mathrm{C}$, and the resulting suspension was treated with a solution of $\mathrm{Fe}(\mathrm{OAc})_{3}(100 \mathrm{~mL}, 0.1 \mathrm{~mol} / \mathrm{L})$ in water (providing an excess of $\mathrm{Fe}^{3+}$ ). This mixture was then heated under reflux for $4 \mathrm{~d}$. It is noteworthy that the acetate ion performed effectively as a base to keep the hydrogen ion concentration in the solution sufficiently low so as to achieve high loadings of the catalyst [8]. A complete exchange between the cations and the hydrogen ions of the $\mathrm{P}-\mathrm{OH}$ groups could not be achieved in less than $3 \mathrm{~d}$ or below $80{ }^{\circ} \mathrm{C}$ [13]. The resulting slurry was filtered while hot to give a light yellow solid that was washed with distilled water until no $\mathrm{Fe}^{3+}$ ions could be detected in the filtrate (that is, until the filtrate was colorless). The solid product was then dried at $100{ }^{\circ} \mathrm{C}$ for $24 \mathrm{~h}$ before being calcined at $600{ }^{\circ} \mathrm{C}$ for $4 \mathrm{~h}$ to give the final product, $\mathrm{Fe}_{1 / 3}\left[\mathrm{Zr}_{2}\left(\mathrm{PO}_{4}\right)_{3}\right]$, as a pale yellow solid (Scheme 1).

\subsection{Catalyst characterization}

The chemical composition of the ZPFe catalyst was evaluated both before and after the catalytic reaction by ICP-OES using an Optima 7300 V ICP-OES spectrometer (PerkinElmer). Cata-

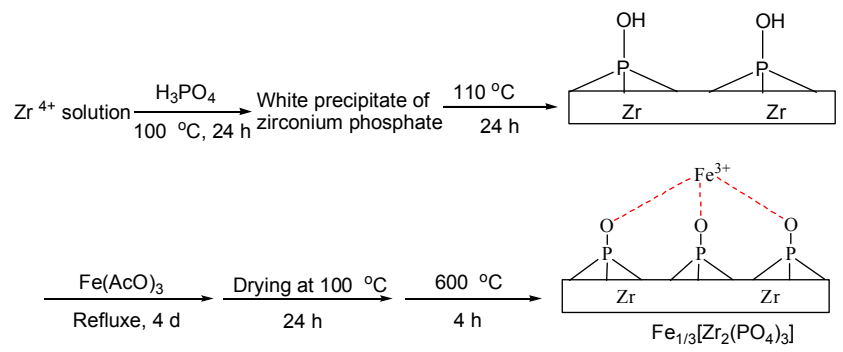

Scheme 1. Summary of the ZPFe preparation procedure. 


$$
\begin{aligned}
& \mathrm{R}-\mathrm{OH}+\mathrm{Ac}_{2} \mathrm{O} \underset{\mathrm{R}=\text { aryl, alkyl, benzyl }}{\stackrel{\mathrm{ZPFe}(1 \mathrm{~mol} \%)}{40^{\circ} \mathrm{C}, 10-45 \mathrm{~min}}} \mathrm{R}-\mathrm{OAc}+\mathrm{CH}_{3} \mathrm{CO}_{2} \mathrm{H}
\end{aligned}
$$

Scheme 2. Summary of the acetylation procedure.

lyst samples were also ground into fine powders and analyzed by XRD on a Philips X'pert X-ray diffractometer. The specific surface areas of the samples were determined from their $\mathrm{N}_{2}$ adsorption-desorption isotherms, using the BET method, on a Quantachrome ChemBET 3000 instrument. Each sample was degassed at $400{ }^{\circ} \mathrm{C}$ for $2 \mathrm{~h}$ before being analyzed to remove any adsorbed species from the surface. The surface morphologies of the ZP and ZPFe materials were determined by SEM observations employing a Philips XL microscope. TEM images of ZPFe were obtained on a CENTRA 100 TEM system (Zeiss).

\subsection{General experimental procedure for the acetylation of substrates under solvent-free conditions}

ZPFe (1 mol\%) was added to a mixture of alcohol (1 mmol) and AA ( $2 \mathrm{mmol})$, and the resulting mixture was stirred at $40{ }^{\circ} \mathrm{C}$ for a specified time (Scheme 2). Upon completion of the reaction (as determined by gas chromatography), the catalyst was separated from the reaction mixture by centrifuge, after which the supernatant was collected and diluted with a $10 \% \mathrm{NaHCO}_{3}$ solution $(10 \mathrm{~mL})$ before being extracted with $\mathrm{Et}_{2} \mathrm{O}(2 \times 10 \mathrm{~mL})$. The combined organic extracts were washed and then dried over anhydrous $\mathrm{CaCl}_{2}$ before being evaporated to dryness under vacuum to give the desired product. In some cases, it was necessary to purify the product by column chromatography on a silica gel column with elution by a mixture of cyclohexane and ethyl acetate.

\subsection{Recyclability studies}

To examine the recyclability of the catalyst, the ZPFe was recovered from the reaction media and re-used. Following each use, the catalyst was separated from the reaction mixture by centrifugation, washed sequentially with ethanol and water, dried at $110^{\circ} \mathrm{C}$ for $2 \mathrm{~h}$, and then activated at $450{ }^{\circ} \mathrm{C}$ for $2 \mathrm{~h}$.

\section{Results and discussion}

\subsection{Catalyst characterization}

The data resulting from ICP-OES analyses of the ZP and ZPFe are shown in Table 1. The results obtained in the current study for ZPFe were compared with those reported previously

Table 1

Elemental compositions of iron zirconium phosphate catalysts (at\%).

\begin{tabular}{lcccc}
\hline Sample & Fe & 0 & Zr & P \\
\hline ZP & - & 63.1 & 13.6 & 23.3 \\
ZPFe & 9.7 & 58.7 & 11.9 & 19.7 \\
ZPFe $^{\text {a }}$ & 9.5 & 59.7 & 12.0 & 18.8 \\
ZPFe $^{\text {b }}$ & 4.9 & 63.5 & 12.2 & 19.4 \\
\hline
\end{tabular}

a After run 1.

b After run 7 .

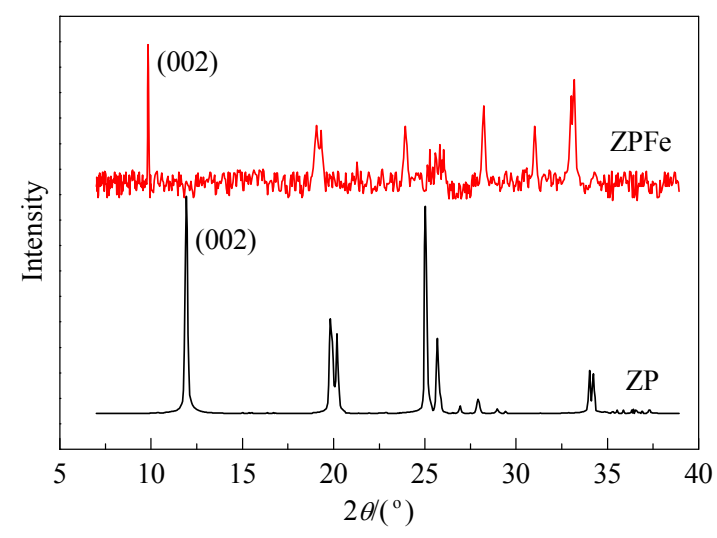

Fig. 1. XRD patterns of powdered ZP and unused ZPFe.

in the literature [8-10]. These results also demonstrate that there was negligible leaching of iron ions into the reaction media during the initial use of the catalyst.

Figure 1 presents the powder XRD patterns of the ZP and ZPFe materials, indicating characteristic reflections in the $2 \theta$ range of $5^{\circ}-40^{\circ}$. The diffraction peak generated by ZP at a $2 \theta$ of approximately $12^{\circ}$ was assigned to a $d_{002}$ basal spacing of $7.5 \AA$ between planes, in good agreement with the patterns previously reported for ZP and its derivatives having a hexagonal crystal system [2].

The ZPFe pattern indicates that the $d$-spacing of the (002) plane in this material was increased, demonstrating that $\mathrm{Fe}^{3+}$ ions intercalated into the ZP interlayers and thus increased the $d_{002}$ basal interlamellar spacing from the original value of $7.5 \AA$ to $9.3 \AA$ A. It is well known that the radii of the $\mathrm{Fe}^{3+}$ ion $(0.64 \AA)$ and the hydrated $\mathrm{Fe}^{3+}$ ion $(3.9 \AA)$ are smaller than the basal spacing of ZP $(7.5 \AA)[66,67]$. These results therefore provide evidence that $\mathrm{Fe}^{3+}$ ions were inserted into the ZP interlayers and increased the basal spacing of the modified ZP during the ion exchange process $[4,9,10,17]$. Taken together, the above characterization data show that ZPFe had been successfully synthesized. The XRD pattern of the ZPFe catalyst after the 7th run demonstrates that the basal spacing of the ZP was approximately $10.5 \AA$, a value only slightly larger than that of the fresh ZPFe catalyst. This increase may have occurred because of the presence of a reduced quantity of $\mathrm{Fe}^{3+}$ ions on the $\mathrm{ZP}$ surface together with an increase in the number of water molecules between the layers, meaning that $\mathrm{Fe}^{3+}$ ions may have been washed off during the regeneration of the catalyst during the process described in Section 2.4 (Table 1).

Figure 2 shows a representative $\mathrm{N}_{2}$ adsorption-desorption isotherm of ZPFe over the relative pressure range $\left(p / p_{0}\right)$ of 0.1-1.0. From these data, the ZPFe surface area was determined to be $107.1 \mathrm{~m}^{2} / \mathrm{g}$. The isotherm exhibits three adsorption stages at $p / p_{0}<0.36,0.36<p / p_{0}<0.92$ and $p / p_{0}>0.92$. The isotherm also shows a typical type IV shape with a distinct hysteresis loop, characteristic of a mesoporous material [68]. The hysteresis loop (type H3) is associated with the occurrence of capillary condensation in the mesopores, indicating the presence of a mesoporous structure in the ZPFe catalyst. The observed increase in adsorption at higher $p / p_{0}$ values shows 


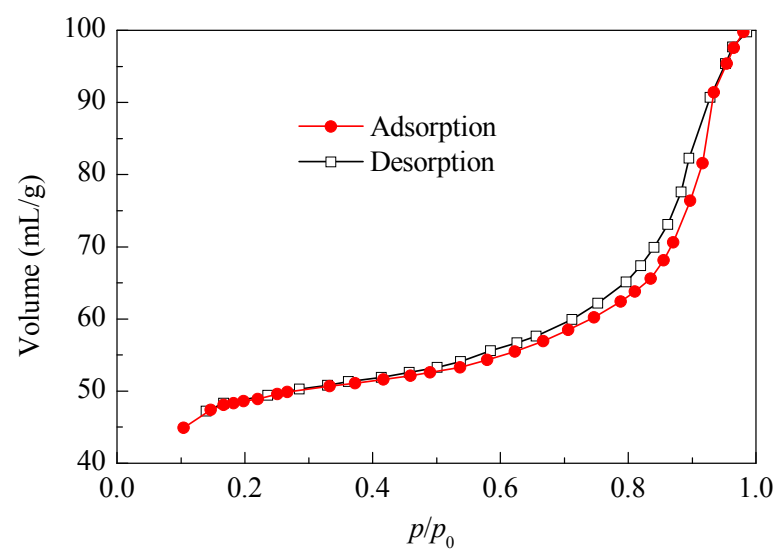

Fig. 2. $\mathrm{N}_{2}$ adsorption-desorption isotherm of ZPFe.

the presence of larger mesopores in the sample $[9,10]$. The surface area of the ZPFe following the 7th run was found to be $82.3 \mathrm{~m}^{2} / \mathrm{g}$.

SEM images of ZP (Fig. 3(a)) demonstrate the presence of hexagonal plates with well-defined shapes and very smooth surfaces. Figures 3(b) and (c) present SEM images of ZPFe, from which it is evident that the structure of ZPFe was much less ordered than that of ZP, and that the ZPFe particles had aggregated to form both sheets and spheres of different shapes and sizes $[4,10]$.

Figure 4 shows TEM images of ZPFe. In these images, the ZPFe catalyst can be seen to have retained the original morphology of ZP (a layered structure) and to consist of particles approximately $150 \mathrm{~nm}$ in size. These images also show nanoparticles of different sizes on the smooth surface of the ZP.

\subsection{Catalytic activity in acetylation and a proposed mechanism}

The conversion of phenol ( $1 \mathrm{mmol})$ to phenyl acetate was selected as a model reaction to optimize the reaction conditions. The conversion was performed in the presence of ZPFe ( $1 \mathrm{~mol} \%$ ) and AA ( $2 \mathrm{mmol}$ ) in various solvents, as well as under solvent-free conditions. As shown in Table 2, the use of ZPFe as a catalyst under solvent-free conditions provided higher yields and shorter reaction times than those achieved under conventional conditions.

Having determined the optimized conditions, we proceeded to evaluate the scope and generality of the method using various alcohols and phenols (Table 3). The hydroxyl groups of

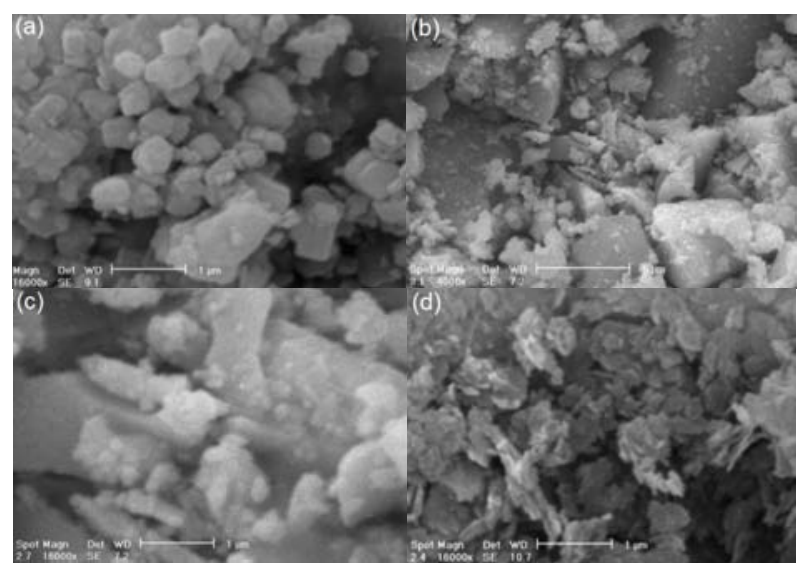

Fig. 3. SEM images of ZP (a), unused ZPFe (b, c) and ZPFe after the 7th run (d).

\section{Table 2}

Conversions of phenol to phenylacetate in different solvents and under solvent-free conditions in the presence of ZPFe (1 mol\%).

\begin{tabular}{lccc}
\hline Entry & Solvent $^{\mathrm{a}}$ & Yield $^{\mathrm{b}}(\%)$ & Time $(\mathrm{min})$ \\
\hline 1 & Dichloromethane & Trace & 120 \\
2 & Diethylether & Trace & 120 \\
3 & Acetonitrile & Trace & 120 \\
4 & Cyclohexane $_{5}$ & 52 & 60 \\
5 & Solvent-free $^{\mathrm{c}}$ & 90 & 15 \\
\hline
\end{tabular}

a The reaction was carried out in $5 \mathrm{~mL}$ of solvent under reflux conditions.

${ }^{\mathrm{b}}$ The yields refer to isolated pure products.

c The reaction was carried out at $40{ }^{\circ} \mathrm{C}$.

each alcohol and phenol were converted to the corresponding acetate in good yields following short reaction times when using three or four equivalents of AA (Table 3, entries 8-10 and 20). Furthermore, the products were readily isolated from the reaction mixtures by a simple filtration followed by a standard work-up procedure. Phenols reacted smoothly under the optimized conditions (Table 3, entries 1-15), with the corresponding acetates being formed in yields of $80 \%-95 \%$. Furthermore, no by-products (such as those resulting from a Fries rearrangement) were observed when reacting substituted phenols. The presence of the electron-donating substituents $-\mathrm{CH}_{3}$, $-\mathrm{OCH}_{3}$ and $-\mathrm{OH}$ on the phenol ring significantly increased the rate of the acetylation reaction (Table 3, entries 2-10), with shorter reaction times being observed in these cases. In contrast, the presence of electron withdrawing groups (carboxyl and nitro groups and halogens) on the phenol ring decreased

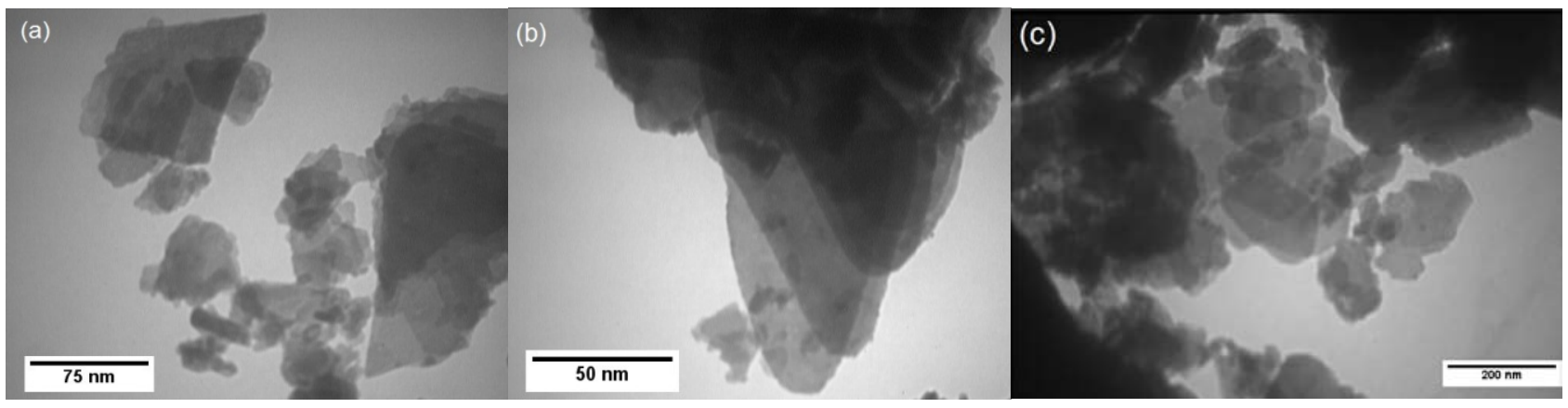

Fig. 4. TEM images of unused ZPFe under different magnifications ((a) and (b)) and ZPFe after the 7th run (c). 
Table 3

Acetylation of various alcohols with AA as catalyzed by ZPFe under solvent-free conditions.

\begin{tabular}{|c|c|c|c|c|c|c|}
\hline Entry & Substrate & Product a & Time (min) & Temperature $\left({ }^{\circ} \mathrm{C}\right)$ & Substrate:AA molar ratio & Yield b $(\%)$ \\
\hline 1 & $\mathrm{C}_{6} \mathrm{H}_{5} \mathrm{OH}$ & $\mathrm{C}_{6} \mathrm{H}_{5} \mathrm{OAc}$ & 15 & 40 & $1: 2$ & 90 \\
\hline 2 & $2-\mathrm{Me}^{-} \mathrm{C}_{6} \mathrm{H}_{4} \mathrm{OH}$ & 2-Me- $\mathrm{C}_{6} \mathrm{H}_{4} \mathrm{OAc}$ & 15 & 40 & $1: 2$ & 91 \\
\hline 3 & 4- $\mathrm{Me}-\mathrm{C}_{6} \mathrm{H}_{4} \mathrm{OH}$ & 4-Me- $\mathrm{C}_{6} \mathrm{H}_{4} \mathrm{OAc}$ & 10 & 40 & $1: 2$ & 95 \\
\hline 4 & $2,6-(\mathrm{Me})_{2}-\mathrm{C}_{6} \mathrm{H}_{3} \mathrm{OH}$ & $2,6-(\mathrm{Me})_{2}-\mathrm{C}_{6} \mathrm{H}_{3} \mathrm{OAc}$ & 30 & 40 & $1: 2$ & 87 \\
\hline 5 & $2,4-(\mathrm{Me})_{2}-\mathrm{C}_{6} \mathrm{H}_{3} \mathrm{OH}$ & $2,4-(\mathrm{Me})_{2}-\mathrm{C}_{6} \mathrm{H}_{3} \mathrm{OAc}$ & 10 & 40 & $1: 2$ & 94 \\
\hline 6 & $4-\left(\mathrm{CH}_{3}\right)_{3} \mathrm{C}-\mathrm{C}_{6} \mathrm{H}_{4} \mathrm{OH}$ & 4- $\left(\mathrm{CH}_{3}\right)_{3} \mathrm{C}-\mathrm{C}_{6} \mathrm{H}_{4} \mathrm{OAc}$ & 10 & 40 & $1: 2$ & 92 \\
\hline 7 & $4-\mathrm{MeO}-\mathrm{C}_{6} \mathrm{H}_{4} \mathrm{OH}$ & $4-\mathrm{MeO}-\mathrm{C}_{6} \mathrm{H}_{4} \mathrm{OAc}$ & 10 & 40 & $1: 2$ & 95 \\
\hline 8 & $4-\mathrm{OH}-\mathrm{C}_{6} \mathrm{H}_{4} \mathrm{OH}$ & 4-AcO- $\mathrm{C}_{6} \mathrm{H}_{4} \mathrm{OAc}$ & 15 & 40 & $1: 3$ & 91 \\
\hline 9 & $3-\mathrm{OH}-\mathrm{C}_{6} \mathrm{H}_{4} \mathrm{OH}$ & $3-\mathrm{AcO}-\mathrm{C}_{6} \mathrm{H}_{4} \mathrm{OAc}$ & 15 & 40 & $1: 3$ & 90 \\
\hline 10 & 2,3-Di-OH- $\mathrm{C}_{6} \mathrm{H}_{3} \mathrm{OH}$ & 2,3-Di-AcO- $\mathrm{C}_{6} \mathrm{H}_{3} \mathrm{OAc}$ & 30 & 40 & $1: 4$ & 88 \\
\hline 11 & $4-\mathrm{Cl}-\mathrm{C}_{6} \mathrm{H}_{4} \mathrm{OH}$ & $4-\mathrm{Cl}-\mathrm{C}_{6} \mathrm{H}_{4} \mathrm{OAc}$ & 45 & 60 & $1: 2$ & 82 \\
\hline 12 & $4-\mathrm{Br}-\mathrm{C}_{6} \mathrm{H}_{4} \mathrm{OH}$ & 4-Br- $\mathrm{C}_{6} \mathrm{H}_{4} \mathrm{OAc}$ & 45 & 60 & $1: 2$ & 87 \\
\hline 13 & $4-\mathrm{NO}_{2}-\mathrm{C}_{6} \mathrm{H}_{4} \mathrm{OH}$ & $4-\mathrm{NO}_{2}-\mathrm{C}_{6} \mathrm{H}_{4} \mathrm{OAc}$ & 45 & 60 & $1: 2$ & 80 \\
\hline 14 & $2-\mathrm{OH}-\mathrm{C}_{6} \mathrm{H}_{4} \mathrm{CO}_{2} \mathrm{H}$ & 2-AcO- $\mathrm{C}_{6} \mathrm{H}_{4} \mathrm{CO}_{2} \mathrm{H}$ & 35 & 60 & $1: 2$ & 89 \\
\hline 15 & $4-\mathrm{OH}-\mathrm{C}_{6} \mathrm{H}_{4} \mathrm{CO}_{2} \mathrm{H}$ & 4-AcO- $\mathrm{C}_{6} \mathrm{H}_{4} \mathrm{CO}_{2} \mathrm{H}$ & 30 & 60 & $1: 2$ & 90 \\
\hline 16 & 2-Naphthol & 2-Naphthyl acetate & 15 & 40 & $1: 2$ & 92 \\
\hline 17 & $\mathrm{C}_{6} \mathrm{H}_{5} \mathrm{CH}_{2} \mathrm{OH}$ & $\mathrm{C}_{6} \mathrm{H}_{5} \mathrm{CH}_{2} \mathrm{OAc}$ & 15 & 40 & $1: 2$ & 91 \\
\hline 18 & $2-\mathrm{MeO}-\mathrm{C}_{6} \mathrm{H}_{4} \mathrm{CH}_{2} \mathrm{OH}$ & $2-\mathrm{MeO}-\mathrm{C}_{6} \mathrm{H}_{4} \mathrm{CH}_{2} \mathrm{OAc}$ & 15 & 40 & $1: 2$ & 92 \\
\hline 19 & $4-\mathrm{MeO}-\mathrm{C}_{6} \mathrm{H}_{4} \mathrm{CH}_{2} \mathrm{OH}$ & $4-\mathrm{MeO}-\mathrm{C}_{6} \mathrm{H}_{4} \mathrm{CH}_{2} \mathrm{OAc}$ & 10 & 40 & $1: 2$ & 95 \\
\hline 20 & $4-\mathrm{OH}-\mathrm{C}_{6} \mathrm{H}_{4} \mathrm{CH}_{2} \mathrm{OH}$ & $4-\mathrm{AcO}-\mathrm{C}_{6} \mathrm{H}_{4} \mathrm{CH}_{2} \mathrm{OAc}$ & 10 & 40 & $1: 3$ & 92 \\
\hline 21 & $4-\mathrm{Cl}-\mathrm{C}_{6} \mathrm{H}_{4} \mathrm{CH}_{2} \mathrm{OH}$ & 4-Cl- $\mathrm{C}_{6} \mathrm{H}_{4} \mathrm{CH}_{2} \mathrm{OAc}$ & 15 & 40 & $1: 2$ & 84 \\
\hline 22 & $4-\mathrm{NO}_{2}-\mathrm{C}_{6} \mathrm{H}_{4} \mathrm{CH}_{2} \mathrm{OH}$ & $4-\mathrm{NO}_{2}-\mathrm{C}_{6} \mathrm{H}_{4} \mathrm{CH}_{2} \mathrm{OAc}$ & 15 & 40 & $1: 2$ & 82 \\
\hline 23 & 1-Hexanol & 1-Hexyl acetate & 10 & 40 & $1: 2$ & 95 \\
\hline 24 & Cyclohexanol & Cyclohexyl acetate & 10 & 40 & $1: 2$ & 92 \\
\hline 25 & 3-Methyl-1-butanol & 3-Methylbutyl acetate & 10 & 40 & $1: 2$ & 95 \\
\hline 26 & $\left(\mathrm{CH}_{3}\right)_{3} \mathrm{C}-\mathrm{OH}$ & $\left(\mathrm{CH}_{3}\right)_{3} \mathrm{C}-\mathrm{OAc}$ & 20 & 40 & $1: 2$ & 87 \\
\hline
\end{tabular}

${ }^{a}$ All products were characterized by comparison of GC-MS, IR and ${ }^{1} \mathrm{H}$ NMR spectral data with those of authentic samples or reported data.

b Isolated yield.

the reaction rate (Table 3 , entries 11-15). The optimized reaction conditions were also successfully applied to obtain the acetylation of benzylic alcohols bearing either electron-withdrawing or electron-donating groups, without the formation of any by-products resulting from oxidation reactions (Table 3 , entries 17-22). In the case of deactivated aromatic rings (Table 3 , entries 21 and 22), the acetylated products were obtained in much lower yields and required longer reaction times than the corresponding activated aromatic systems (Table 3, entries 18-20). It was also observed that the reaction times required for the acetylation of the phenols were longer than those required for the benzylic alcohols.

This difference in the reaction times was attributed to the lower nucleophilicity of phenols compared with benzylic alcohols because of the delocalization of the lone pairs of electrons on the phenolic oxygen throughout the benzene ring $[43,49,51]$. To further extend the scope of the ZPFe catalyst, we also investigated the acetylation of several aliphatic alcohols, including 1-hexanol, cyclohexanol, 3-methyl-1-butanol and tert-butanol, under the optimized conditions (Table 3, entries 23-26).

The acetylation reactions of 1-hexanol cyclohexanol and 3-methyl-1-butanol proceeded much more rapidly than the acetylation of tert-butanol, most likely because of the steric hindrance provided by the tert-butyl group. A schematic representation of the ZPFe-mediated acetylation process is provided in Scheme 3. To develop a better understanding of the role of the ZPFe catalyst in the acetylation reaction, we also investigated the acetylation of phenol, 4-hydroxyphenol and benzyl alcohol in the absence of the catalyst. As expected, no products were formed in any of these reactions, demonstrating the importance of the catalyst in the acetylation process. All the acetylated products formed in the current study were characterized by gas chromatography-mass spectrometry (GC-MS, Agilent 5975C), Fourier transform infrared spectroscopy (FT-IR, JASCO FT-IR 680 plus) and ${ }^{1} \mathrm{H}$ nuclear magnetic resonance (NMR, Bruker-Avance AQS $400 \mathrm{MHz}$ spectrometer). The resulting spectra were compared with data obtained from standard samples or data from the literature [28,44,45,47-53].

The reusability of the ZPFe catalyst was investigated under the optimum reaction conditions for the acetylation of phenol, and the results are shown in Table 4. The elemental composition of the catalyst remained largely unchanged following its 7th use, although the amount of iron in the catalyst was reduced by almost $50 \%$ compared with the first run (Table 1 ). The recycled ZPFe catalyst gave a similar product yield to the

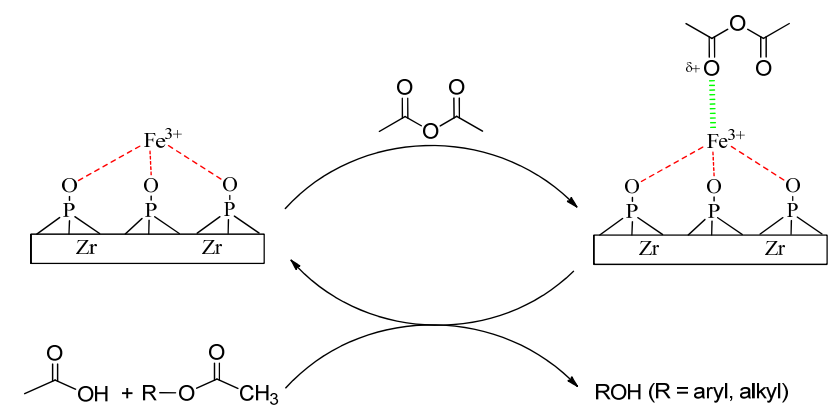

Scheme 3. Summary of the acetylation mechanism. 
Table 4

Percent yields obtained during catalyst reuse under the optimum reaction conditions for acetylation of phenol.

\begin{tabular}{lcccccccc}
\hline Run & Fresh & 1 & 2 & 3 & 4 & 5 & 6 & 7 \\
\hline Yield (\%) & 90 & 90 & 90 & 88 & 87 & 85 & 83 & 70 \\
\hline
\end{tabular}
Reaction conditions: Phenol (1 mmol), $\mathrm{Ac}_{2} \mathrm{O}(2 \mathrm{mmol})$, catalyst (1 $\operatorname{mol} \%), 40^{\circ} \mathrm{C}$.

freshly prepared catalyst up until the 6th cycle.

The catalytic efficiency of ZPFe was compared with those reported for several catalysts and reaction protocols, and the results are summarized in Table 5. Using the current method, phenol was converted to acetyl phenol in $91 \%$ yield following a reaction time of less than $15 \mathrm{~min}$ at $40{ }^{\circ} \mathrm{C}$ (Table 5, entry 18).
Although some of the other catalysts performed well for the same reaction (Table 5, entries 2, 6, and 10), they invariably needed longer reaction times to generate suitable yields (Table 5 , entries $3,6,7,9,11,13$, and 14) or required the use of a solvent (Table 5, entries $4,6,7,9$, and 12). It is noteworthy that the more reactive compound acetyl chloride was required in one case, involving reaction at room temperature (Table 5, entry 5). Furthermore, this reaction required a longer reaction time to afford a similar yield of the acetylated product to the current protocol. Some of the previously reported protocols used acetic acid as the acetylating agent, which is a much greener reagent than acetyl chloride (Table 5 , entries 4,8 , and 15). However, these reactions also required longer reaction times $(3-15 \mathrm{~h})$, high temperatures $\left(70-110^{\circ} \mathrm{C}\right)$ and a large

Table 5

Comparison of protocols for the acylations of phenol and benzyl alcohol.

\begin{tabular}{|c|c|c|c|c|c|c|c|}
\hline Entry & Catalyst & $T\left({ }^{\circ} \mathrm{C}\right)$ & Time (min) & $\mathrm{Ac}_{2} \mathrm{O}$ (equiv.) & Yield (\%) & Solvent & Ref. \\
\hline 1 & ZPZn & 60 & 45 & 2 & 89 & - & {$[22]$} \\
\hline 2 & $\mathrm{~B}\left(\mathrm{C}_{6} \mathrm{~F}_{5}\right)_{3}$ & RT & 15 & 1.2 & 92 & - & {$[30]$} \\
\hline 3 & $\mathrm{ZnCl}_{2}$ & RT & 150 & 1 & 40 & - & [32] \\
\hline 4 & Borate zirconia & 110 & 840 & $5^{a}$ & 10 & Toluene & [33] \\
\hline 5 & $\mathrm{ZnO}$ & $\mathrm{RT}$ & 60 & $1.2^{b}$ & 90 & - & [34] \\
\hline 6 & $\mathrm{Ce}(\mathrm{OTf})_{3}$ & RT & 150 & 1.5 & 98 & $\mathrm{CH}_{3} \mathrm{CN}$ & [35] \\
\hline 7 & $\mathrm{SiO}_{2}-\mathrm{ZnCl}_{2}$ & 80 & 210 & 1.2 & 83 & $\mathrm{CH}_{3} \mathrm{CN}$ & [36] \\
\hline 8 & $\mathrm{H}_{3} \mathrm{PW}_{12} \mathrm{O}_{40}$ & 70 & 180 & $5^{\text {a }}$ & 3 & - & {$[37]$} \\
\hline 9 & $\mathrm{DMAP} \cdot \mathrm{HCl}$ & RT & 600 & 1.1 & 99 & Toluene & [38] \\
\hline 10 & $\mathrm{Cu}\left(\mathrm{BF}_{4}\right)_{2}$ & RT & 30 & 1 & 97 & - & [39] \\
\hline 11 & Silica sulfamic acid & RT & 180 & $3 \mathrm{~mL}^{\mathrm{c}}$ & - & - & [40] \\
\hline 12 & [bmim][OTs] & 50 & 10 & 2 & 97 & {$[\mathrm{bmim}]\left[\mathrm{BF}_{4}\right]$} & [43] \\
\hline 13 & {$[\mathrm{MMPPA}]\left[\mathrm{HSO}_{4}\right]$} & RT & 120 & 1.5 & 99 & - & [44] \\
\hline 14 & SBNPSA & RT & 180 & $3 \mathrm{~mL}^{\mathrm{c}}$ & - & - & [46] \\
\hline 15 & Yttria-zirconia & 110 & 900 & $5^{a}$ & 77 & - & [54] \\
\hline 16 & $\mathrm{Ni} / \mathrm{SiO}_{2}$ & 65 & 240 & 1.5 & 90 & $\mathrm{CH}_{3} \mathrm{CN}$ & [58] \\
\hline 17 & $\mathrm{NiCl}_{2}$ & RT & 30 & 4 & 95 & - & [61] \\
\hline 18 & $\mathrm{ZPFe}$ & 40 & 15 & 2 & 90 & - & This work \\
\hline 19 & $\mathrm{ZrOCl}_{2} \cdot 8 \mathrm{H}_{2} \mathrm{O}$ & 40 & 15 & 2 & 92 & - & This work \\
\hline 20 & $\mathrm{ZP}$ & 40 & 15 & 2 & 70 & - & This work \\
\hline 21 & ZPZn & 60 & 30 & 2 & 91 & - & [22] \\
\hline 22 & $\mathrm{~B}\left(\mathrm{C}_{6} \mathrm{~F}_{5}\right)_{3}$ & RT & 2 & 1.2 & 98 & - & [30] \\
\hline 23 & $\mathrm{ZnCl}_{2}$ & RT & 180 & 1 & 63 & - & [32] \\
\hline 24 & Borated zirconia & 110 & 840 & $5^{\text {a }}$ & 25 & Toluene & [34] \\
\hline 25 & $\mathrm{SiO}_{2}-\mathrm{ZnCl}_{2}$ & 80 & 180 & 1.2 & 90 & $\mathrm{CH}_{3} \mathrm{CN}$ & {$[36]$} \\
\hline 26 & Silica sulfamic acid & RT & 15 & $3 \mathrm{~mL}^{\mathrm{c}}$ & 93 & - & [40] \\
\hline 27 & $\mathrm{Cp}_{2} \mathrm{ZrCl}_{2}$ & RT & 600 & 1 & 93 & - & [41] \\
\hline 28 & {$[\mathrm{TMBSA}]\left[\mathrm{HSO}_{4}\right]$} & $\mathrm{RT}$ & 120 & 1.1 & 99 & - & [42] \\
\hline 29 & {$[\mathrm{MMPPA}]\left[\mathrm{HSO}_{4}\right]$} & $\mathrm{RT}$ & 120 & 1.1 & 99 & - & {$[44]$} \\
\hline 30 & SaSA & Reflux & 120 & 1.2 & 85 & $\mathrm{CH}_{2} \mathrm{Cl}_{2}$ & [45] \\
\hline 31 & SBNPSA & RT & 45 & $3 \mathrm{~mL}^{\mathrm{c}}$ & 91 & - & [46] \\
\hline 32 & Yttria-zirconia & 110 & 240 & $5^{a}$ & 94 & - & [54] \\
\hline 33 & $\mathrm{CoCl}_{2}$ & $\mathrm{RT}$ & 240 & 2 & 98 & - & [55] \\
\hline 34 & $\mathrm{NiCl}_{2}$ & RT & 30 & 4 & 98 & - & [61] \\
\hline 35 & $\mathrm{ZPFe}$ & 40 & 15 & 2 & 91 & - & This work \\
\hline 36 & $\mathrm{ZrOCl}_{2} \cdot 8 \mathrm{H}_{2} \mathrm{O}$ & 40 & 15 & 2 & 90 & - & This work \\
\hline 37 & $\mathrm{ZP}$ & 40 & 15 & 2 & 75 & - & This work \\
\hline
\end{tabular}

a Acetic acid as the acetylating agent.

${ }^{\mathrm{b}}$ Acetyl chloride as the acetylating agent.

c Ethyl formate as the acetylating agent. 
excess of acid acetic in almost all cases. The acetylation of phenol was also investigated using $\mathrm{ZrOCl}_{2} \cdot 8 \mathrm{H}_{2} \mathrm{O}$ and $\mathrm{ZP}$ under our optimized reaction conditions (Table 5 , entries 19 and 20). $\mathrm{ZrOCl}_{2} \cdot 8 \mathrm{H}_{2} \mathrm{O}$ gave an excellent yield of the desired product, but was much more difficult to recover and reuse than the ZPFe catalyst. ZP gave a lower yield (70\%) than ZPFe. The use of ZPZn as a catalyst, however, provided a similar result to that obtained when using ZPFe (Table 5, entry 1), with a $20 \mathrm{~mol} \%$ loading of ZPZn providing the acetyl phenol product in $89 \%$ yield following a reaction time of $45 \mathrm{~min}$ [22].

Based on this comparison process, ZPFe was identified as the best catalyst for this transformation in terms of the reaction time and the loading of the catalyst. Benzyl alcohol was also acetylated under the optimized conditions to give the acetylated product in 91\% yield following a reaction time of $15 \mathrm{~min}$ at $40{ }^{\circ} \mathrm{C}$ (Table 5, entry 35). This protocol was also compared with a variety of different previously reported procedures for the same transformation, and the results are shown in Table 5. When the reaction was conducted at room temperature in the presence of a different catalyst, longer reaction times were generally required to reach completion (Table 5 , entries 23, 27-29, and 33). The use of $\mathrm{ZPZn}, \mathrm{ZrOCl}_{2} \cdot 8 \mathrm{H}_{2} \mathrm{O}$ or $\mathrm{ZP}$ as a catalyst under the optimized conditions provided the desired product in yields of $91 \%, 90 \%$ and $75 \%$, respectively (Table 5 , entries 21, 36, and 37). However, large excesses of the catalyst were required in all three cases, and significant difficulties were encountered during the recovery of these catalysts. These reactions also resulted in lower yields of the product. There were some benefits to using these catalysts, in that they used acetic acid as the acetylating agent rather than AA, even though all required longer reaction times, higher temperatures and a large excess of acetic acid to reach completion (Table 5, entries 24 and 32). ${ }^{1} \mathrm{H}$ NMR and FT-IR spectral data for selected compounds from Table 3 are provided below.

$\mathrm{C}_{6} \mathrm{H}_{5} \mathrm{OAc}$ (Table 3, entry 1). ${ }^{1} \mathrm{H}$ NMR (400 MHz, $\mathrm{CDCl}_{3}$ ): $\delta=$ $7.2(\mathrm{t}, J=7.9 \mathrm{~Hz}, 2 \mathrm{H}), 7.1(\mathrm{t}, J=7.5 \mathrm{~Hz}, 1 \mathrm{H}), 7.0(\mathrm{t}, J=7.9 \mathrm{~Hz}, 2 \mathrm{H})$, 2.3 (s, 3H); IR (KBr): 3055, 2915, 1753, 1581, 1485, 1364, $1179,1014,916,876,804,739,675 \mathrm{~cm}^{-1}$.

4-Me- $\mathrm{C}_{6} \mathrm{H}_{4} \mathrm{OAc}$ (Table 3, entry 3). ${ }^{1} \mathrm{H}$ NMR (400 MHz, $\left.\mathrm{CDCl}_{3}\right)$ : $\delta=7.04(\mathrm{~d}, J=7.9 \mathrm{~Hz}, 2 \mathrm{H}), 6.82(\mathrm{~d}, J=7.9 \mathrm{~Hz}, 2 \mathrm{H}), 2.35(\mathrm{~s}, 3 \mathrm{H})$, 2.27 (s, 3H); IR (KBr): 3045, 2936, 1773, 1608, 1515, 1442, $1378,1207,1187,1173,1014,947,915,832,816 \mathrm{~cm}^{-1}$.

4- $\left(\mathrm{CH}_{3}\right)_{3} \mathrm{C}-\mathrm{C}_{6} \mathrm{H}_{4} \mathrm{OAc}$ (Table 3, entry 6). ${ }^{1} \mathrm{H}$ NMR (400 MHz, $\left.\mathrm{CDCl}_{3}\right): \delta=7.37(\mathrm{~d}, J=8.25 \mathrm{~Hz}, 2 \mathrm{H}), 7.18(\mathrm{~d}, J=8.25 \mathrm{~Hz}, 2 \mathrm{H})$, 2.27 (s, 3H), 1.24 (s, 9H); IR (KBr): 3052, 2971, 2918, 1759, $1600,1517,1448,1373,1279,1211,1116,1026,924,841,686$ $\mathrm{cm}^{-1}$.

4-Cl- $\mathrm{C}_{6} \mathrm{H}_{4} \mathrm{OAc}$ (Table 3, entry 9). ${ }^{1} \mathrm{H}$ NMR (400 MHz, $\mathrm{CDCl}_{3}$ ): $\delta=7.43(\mathrm{~d}, J=8.4 \mathrm{~Hz}, 2 \mathrm{H}) 6.75(\mathrm{~d}, J=8.4 \mathrm{~Hz}, 2 \mathrm{H}), 2.24(\mathrm{~s}, 3 \mathrm{H})$; IR (KBr): 3075, 2939, 1765, 1641, 1591, 1488, 1370, 1200, $1163,1014,941,845,798,720 \mathrm{~cm}^{-1}$.

2-AcO- $\mathrm{C}_{6} \mathrm{H}_{4} \mathrm{CO}_{2} \mathrm{H}$ (Table 3, entry 12). ${ }^{1} \mathrm{H}$ NMR (400 MHz, $\left.\mathrm{CDCl}_{3}\right): \delta=10.4(\mathrm{~s}, 1 \mathrm{H}), 7.95-7.12(\mathrm{~m}, 4 \mathrm{H}), 2.35(\mathrm{~s}, 3 \mathrm{H})$; IR (KBr): 3426-2996, 2872, 1752, 1687, 1607, 1458, 1306, 1188, $917,753,706 \mathrm{~cm}^{-1}$.

4-MeO- $\mathrm{C}_{6} \mathrm{H}_{4} \mathrm{CH}_{2} \mathrm{OAc}$ (Table 3, entry 17). ${ }^{1} \mathrm{H}$ NMR (400 MHz, $\left.\mathrm{CDCl}_{3}\right): \delta=7.15(\mathrm{~d}, J=8.5 \mathrm{~Hz}, 2 \mathrm{H}), 6.78(\mathrm{~d}, J=8.5 \mathrm{~Hz}, 2 \mathrm{H}), 5.0(\mathrm{~s}$,
2H), 3.65 (s, 3H), 2.2 (s, 3H); IR (KBr): 3011, 2943, 2826, 1729, 1613, 1518, 1460, 1363, 1243, 1176, 1120, 1031, 960, 823 $\mathrm{cm}^{-1}$.

3-Methylbutyl acetate (Table 3, entry 23). ${ }^{1} \mathrm{H}$ NMR (400 $\left.\mathrm{MHz} \mathrm{CDCl}_{3}\right): \delta=4.18(\mathrm{t}, J=6.6 \mathrm{~Hz}, 2 \mathrm{H}), 2.1(\mathrm{~s}, 3 \mathrm{H}), 1.58-1.67$ (m, 1H), 1.43-1.5 (m, 2H), 0.96 (d, J = 3.4, 6H); IR (KBr): 2962, 2935, 1743, 1465, 1430,1249, 1172, 1136, 1065, 962, 857 $\mathrm{cm}^{-1}$.

\section{Conclusions}

ZPFe is an inexpensive, noncorrosive and environmentally benign catalyst that can be readily prepared from simple starting materials. This catalyst was characterized using various analytical methods and the results were in agreement with those reported previously in the literature. In this study, we have developed a simple and efficient procedure for the acetylation of a variety of different alcohols in good yields over short reaction times. There are several notable advantages to this methodology, including a broad substrate scope, the use of AA as an acetylating agent, excellent product yields and a simple work-up procedure resulting from the heterogeneous conditions.

\section{Acknowledgments}

We gratefully acknowledge the funding support received for this project from the Isfahan University of Technology (IUT), IR Iran.

\section{References}

[1] Gan H M, Zhao X G, Song B N, Guo L, Zhang R, Chen C, Chen J Z, Zhu W W, Hou Z S. Chin J Catal (干慧媚, 赵秀阁, 宋宝宁, 郭立, 张然, 陈晨, 陈吉忠, 朱闻闻, 侯震山. 催化学报), 2014, 35: 1148

[2] Sun L, Boo W J, Sue H J, Clearfield A. New J Chem, 2007, 31: 39

[3] Hajipour A R, Karimi H. Mater Lett, 2014, 116: 356

[4] Sun Z Y, Liu Z, Xu L, Yang Y, He Y. Stud Surf Sci Catal, 2004, 154: 1060

[5] Shi Q S, Tan S Z, Ouyang Y S, Yang Q H, Chen A M, Li W R, Shu X L, Feng J, Feng J, Chen Y B. Adv Mater Res, 2011, 151-152: 852

[6] Cai X, Dai G J, Tan S Z, Ouyang Y, Ouyang Y S, Shi Q S. Mater Lett, 2012, 67: 199

[7] Wang Q, Yu J F, Liu J J, Guo Z H, Umar A, Sun L Y. Sci Adv Mater, 2013, 5: 469

[8] Clearfield A, Kalnins J M. J Inorg Nuc Chem, 1978, 40: 1933

[9] Gawande M B, Deshpande S S, Sonavane S U, Jayaram R V. J Mol Catal A, 2005, 241: 151

[10] Khare S, Chokhare R. J Mol Catal A, 2011, 344: 83

[11] Giannoccaro P, Gargano M, Fanizzi A, Ferragina C, Aresta M. Appl Catal A, 2005, 284: 77

[12] Pet'kov V I, Markin A V, Shchelokov I A, Sukhanov M V, Smirnova N N. Russ J Phys Chem, 2007, 81: 1728

[13] Yang Y H, Dai G J, Tan S Z, Liu Y L, Shi Q S, Ouyang Y S. J Rare Earths, 2011, 29: 308

[14] Dai G J, Yu A L, Cai X, Shi Q S, Ouyang Y S, Tan S Z. J Rare Earths, 2012, 30: 820

[15] Zhang Q R, Du W, Pan B C, Pan B J, Zhang W M, Zhang Q J, Xu Z W, Zhang Q X.J Hazard Mater, 2008, 152: 469 


\section{Graphical Abstract}

Chin. J. Catal., 2015, 36: 595-602 doi: 10.1016/S1872-2067(14)60280-1

\section{Acetylation of alcohols and phenols under solvent-free conditions using iron zirconium phosphate}

Abdol R. Hajipour*, Hirbod Karimi, Amir Masti Isfahan University of Technology, Iran;

University of Wisconsin, USA;

Islamic Azad University, Iran

Iron zirconium phosphate was prepared and applied as an efficient and reusable nanocatalyst for the acetylation of alcohols with good yields. This method conforms to several of the guiding principles of green chemistry.

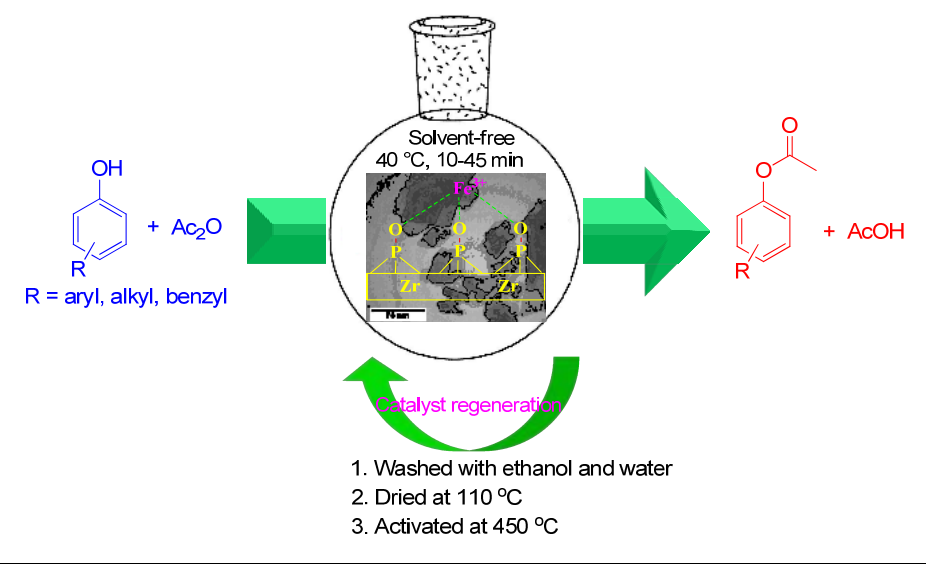

[16] Costantino U, Szirtes L, Kuzmann E, Megyeri J, Lázár K. Solid State Ionics, 2001, 141-142: 359

[17] Gobechiya E R, Kabalov Y K, Orlova A I, Trubach I G, Bykov D M, Kurazhkovskaya V S. Crystallogr Rep, 2004, 49: 390

[18] Khare S, Chokhare R. J Mol Catal A, 2012, 353-354: 138

[19] Wang X Y, Hua W M, Yue Y H, Gao Z. Chem J Chin Univ, 2013, 34 : 1913

[20] Pylinina A I, Mikhalenko I I. Russ J Phys Chem A, 2013, 87: 372

[21] Pylinina A I, Mikhalenko I I. Russ J Phys Chem A, 2011, 85: 2109

[22] Hajipour A R, Karimi H, Karimzadeh M. Monatsh Chem, 2014, 145 : 1461

[23] Hajipour A R, Karimi H. Chin J Catal (催化学报), 2014, 35: 1529

[24] Hajipour A R, Karimi H. Chin J Catal (催化学报), 2014, 35: 1982

[25] Yoon H J, Lee S M, Kim J H, Cho H J, Choi J W, Lee S H, Lee Y S. Tetrahedron Lett, 2008, 49: 3165

[26] Sharghi H, Jokar M, Doroodmand M M. Adv Synth Catal, 2011, 353: 426

[27] Taghavi S A, Moghadam M, Mohammadpoor-Baltork I, Tangestaninejad S, Mirkhani V, Khosropour A R. Inorg Chim Acta, 2011, 377: 159

[28] Montes I, Sanabria D, García M, Castro J, Fajardo J. J Chem Educ, 2006, 83: 628

[29] Reddy T S, Narasimhulu M, Suryakiran N, Mahesh K C, Ashalatha K, Venkateswarlu Y. Tetrahedron Lett, 2006, 47: 6825

[30] Prajapti S K, Nagarsenkar A, Babu B N. Tetrahedron Lett, 2014, 55: 1784

[31] Khaligh N G, Ghasem-Abadi P G. Chin J Catal (催化学报), 2014, 35: 1126

[32] Yadav P, Lagarkha R, Balla Z A. Asia J Chem, 2010, 22: 5155

[33] Osiglio L, Romanelli G, Blanco M. J Mol Catal A, 2010, 316: 52

[34] Tamaddon F, Amrollahi M A, Sharafat L. Tetrahedron Lett, 2005, 46: 7841

[35] Dalpozzo R, De Nino A, Maiuolo L, Procopio A, Nardi M, Bartoli G, Romeo R. Tetrahedron Lett, 2003, 44: 5621

[36] Gupta R, Kumar V, Gupta M, Paul S, Gupta R. Indian J Chem Sec B, 2008, 47B: 1739

[37] Tayebee R, Cheravi F. Bull Korean Chem Soc, 2009, 30: 2899

[38] Liu Z H, Ma Q Q, Liu Y X, Wang Q M. Org Lett, 2014, 16: 236

[39] Chakraborti A K, Gulhane R, Shivani. Synthesis, 2004: 111

[40] Niknam K, Saberi D. Appl Catal A, 2009, 366: 220

[41] Lakshmi Kantam M, Aziz K, Likhar P R. Catal Commun, 2006, 7:
484

[42] Wang W J, Cheng W P, Shao L L, Yang J G. Catal Lett, 2008, 121: 77

[43] Liu Y, Liu L, Lu Y, Cai Y Q. Monatsh Chem, 2008, 139: 633

[44] Yue C B, Liu Q Q, Yi T F, Chen Y. Monatsh Chem, 2010, 141: 975

[45] Shirini F, Zolfigol M A, Abedini M. Monatsh Chem, 2009, 140: 1495

[46] Niknam K, Saberi D. Tetrahedron Lett, 2009, 50: 5210

[47] Shirini F, Khaligh N G. Chin J Catal (催化学报), 2013, 34: 695

[48] Hajjami M, Ghorbani-Choghamarani A, Norouzi M. Chin J Catal (催 化学报), 2012, 33: 1661

[49] Nowrouzi N, Alizadeh S Z. Chin J Catal (催化学报), 2013, 34: 1787

[50] Ghorbani-Choghamarani A, Pourbahar N. Chin J Catal (催化学报), 2012, 33: 1470

[51] Farhadi S, Jahanara K. Chin J Catal (催化学报), 2014, 35: 368

[52] Zarei A, Hajipour A R, Khazdooz L. Synth Commun, 2011, 41: 1772

[53] Hajipour A R, Khazdooz L, Ruoho A E. J Chin Chem Soc, 2009, 56: 398

[54] Kumar P, Pandey R K, Bodas M S, Dagade S P, Dongare M K, Ramaswamy A V.J Mol Catal A, 2002, 181: 207

[55] Iqbal J, Srivastava R R. J Org Chem, 1992, 57: 2001

[56] Dehghani F, Sardarian A R, Doroodmand M M. J Iran Chem Soc, 2014, 11: 673

[57] Constantinou-Kokotou V, Peristeraki A. Synth Commun, 2004, 34: 4227

[58] Alam M, Rahman A, Alandis N M, Shaik M R. Arabian J Chem, 2014, 7: 53

[59] Esmaeilpour M, Sardarian A R. Iran J Sci Technol, Trans A: Sci, 2014, 38: 175

[60] Shirini F, Akbari-Dadamahaleh S, Mohammad-Khah A, Aliakbar A R. C R Chim, 2014, 17: 164

[61] Meshram G, Patil V D. Synth Commun, 2009, 39: 4384

[62] Farhadi S, Jahanara K, Sepahdar A. J Iran Chem Soc, 2014, 11: 1103

[63] Rajabi F, Luque R. Catal Commun, 2014, 45: 129

[64] Hajipour A R, Karimi H. Appl Catal A, 2014, 482: 99

[65] Hajipour A R, Karimi H. Chin J Catal (催化学报), 2014, 35: 1136

[66] Bingham P A, Hannant O M, Reeves-McLaren N, Stennett M C, Hand R J.J Non Cryst Solids, 2014, 387: 47

[67] Pandit A A, Shitre A R, Shengule D R, Jadhav K M. J Mater Sci, 2005, 40: 423

[68] Sing K S W, Everett D H, Haul R A W, Moscou L, Pierotti R A, Rouquerol J, Siemieniewska T. Pure Appl Chem, 1985, 57: 603 